\title{
CFD Simulations on Extinction of Co-Flow Diffusion Flames
}

\author{
JUKKA VAARI ${ }^{1}$, JASON FLOYD ${ }^{2}$, and RANDALL McDERMOTT ${ }^{3}$ \\ ${ }^{1}$ VTT Technical Research Centre of Finland \\ PO Box 1000 \\ FI-02044 VTT, Finland \\ ${ }^{2}$ Hughes Associates, Inc. \\ 3610 Commerce Drive \\ Baltimore, MD 21227-1652, USA \\ ${ }^{3}$ Building and Fire Research Laboratory \\ National Institute of Standards and Technology \\ 100 Bureau Drive \\ Gaithersburg, MD 20899-8600, USA
}

\begin{abstract}
An improved flame extinguishing criterion is implemented to the Fire Dynamics Simulator (FDS) for gaseous suppressants under the lumped species model with transport-limited combustion (infinitely fast chemistry). The criterion considers the total enthalpy of gas mixture as a function of temperature, and evaluates whether a limiting adiabatic flame temperature can be obtained due to combustion in a cell.

The model is validated against a number of experiments in the cup-burner apparatus, a standard means of obtaining the minimum flame-extinguishing concentrations (MEC) for a variety of fuel-suppressant combinations. The results indicate that the model can reproduce the MEC values for all common inert gas agents, as well as some of the fluorinated halocarbon agents.

It is further demonstrated in the paper that the flame extinguishment criterion, although validated using grid cells on the order of $1 \mathrm{~mm}$, is equally applicable to larger cell sizes more appropriate for full-scale simulations. This improves the capability of FDS to predict the performance of full-scale fire suppression systems.
\end{abstract}

KEYWORDS: CFD, suppression, inert gas, cup-burner, NFPA 2001.

\section{NOMENCLATURE LISTING}

$\begin{array}{llll}c_{p} & \text { specific heat }(\mathrm{J} /(\mathrm{kg} \cdot \mathrm{K})) & \eta & \text { Kolmogorov length scale }(\mathrm{m}) \\ h & \text { sensible enthalpy }(\mathrm{J} / \mathrm{kg}) & \mu & \text { dynamic viscosity }(\mathrm{kg} /(\mathrm{m} \cdot \mathrm{s})) \\ H & \text { heat of combustion }(\mathrm{J} / \mathrm{kg}) & v & \text { yield }(\mathrm{kg} / \mathrm{kg}) \\ s & \text { stoichiometric oxygen/fuel ratio } & \rho & \text { density }\left(\mathrm{kg} / \mathrm{m}^{3}\right) \\ S & \text { stress tensor } & \text { subscripts } \\ T & \text { temperature }(\mathrm{K}) & C O & \text { carbon monoxide } \\ W & \text { molecular weight }(\mathrm{kg} / \mathrm{mol}) & C O 2 & \text { carbon dioxide } \\ x & \text { fuel carbon number } & F & \text { fuel } \\ X \quad \text { mole fraction } & g & \text { gas mixture without fuel } \\ Y \quad \text { mass fraction } & S & \text { soot } \\ Z \quad \text { mixture fraction } & O 2 & \text { oxygen } \\ \text { Greek } & & \\ \alpha \quad \text { species } & & \\ \varepsilon \quad \text { energy dissipation rate }\left(\mathrm{m}^{2} / \mathrm{s}^{3}\right) & & \end{array}$

\section{INTRODUCTION}

Fire simulation tools based on computational fluid dynamics (CFD) are increasingly used in performancebased fire safety engineering. The tools are particularly suitable for predicting the spread of heat and smoke in complex enclosures, and generally predicting the 'far-field' conditions, i.e. conditions far from the flame region. Large-scale CFD simulations are typically conducted at a spatial resolution of $0.1 \mathrm{~m}$ or above. Such 
resolution is clearly too coarse compared to the resolution needed to resolve the physical and chemical processes near or in the flame, which occur on a length scale of $0.001 \mathrm{~m}$ or less.

Recently, the International Forum of Fire Research Directors (FORUM) has identified a list of areas where the current capabilities of these tools are exceeded [1]. The top priority on this list was given to prediction of reduction in fire growth and products of combustion provided by enhanced fire detection / alarm systems and alternative suppression systems. Predicting the heat release of a fire poses a challenge to the models not only because of the spatial resolutions required, but also because appropriate physical submodels may be insufficient or missing. Therefore, large-scale simulations are often carried out using a prescribed time evolution of the heat release rate, the 'design fire'.

VTT Technical Research Centre of Finland has carried out a research project with a principal aim of developing the capabilities of one of these simulation tools, the Fire Dynamics Simulator (FDS), to better describe the processes of fire suppression and flame extinguishment by active fire protection systems. A key part of this project has been to identify and perform simulations on full and reduced scale experiments where a flame was extinguished by a diluent or a suppressing agent.

Since its original development in the 1970s, the cup-burner apparatus has become a widely used tool for determining the minimum extinguishing concentration (MEC) for a variety of suppressant/fuel combinations. The MECs from standardized cup-burner experiments are the basis for dimensioning the agent containers for full-scale clean agent fire-extinguishing systems [2]. This paper presents results on FDS simulations on the extinguishment of diffusion flames in a cup-burner apparatus with the purpose of improving the capability of the FDS combustion model to describe flame suppression in full-scale applications.

\section{MODELING APPROACH}

The computations for this study were carried out using the Fire Dynamics Simulator v5 [3], subversion 5855. The governing equations and solution methods are described in [3] except for the new extinguishment criterion and Superbee [4] and CHARM [5] flux limiter schemes that were implemented in the code and used in LES and DNS computations, respectively.

When a 'flux limiter' is chosen for scalar transport, FDS formulates the density and species advection terms in 'flux divergence' form. The reader may think of the flux limiter as a form of interpolation scheme which depends on the local state of the flow field and scalar data. Simple linear interpolation of the cell-centered scalar data to the cell face would result in a central differencing scheme. Such purely centered schemes are known to generate intolerable levels of dispersion error (spurious wiggles) leading to unphysical results such as negative densities or mass fractions outside the range of 0 to 1 . To address this issue, FDS has relied on a 'flux correction' scheme which adds a sufficient amount of numerical diffusion to maintain boundedness. There is, however, more to the problem.

For uniform flow velocity, a fundamental property of the exact solution to the equations governing scalar transport is that the 'total variation' of the scalar field (the sum of the absolute values of the scalar differences between neighboring cells) is preserved or diminished (never increased). In other words, no new extrema are created. Numerical schemes which preserve this property are referred to as total variation diminishing (TVD) schemes. The practical importance of using a TVD scheme for fire modelling is that such a scheme is able to accurately track coherent vortex structure in turbulent flames and does not develop spurious reaction zones.

Recently, FDS has added two popular second-order TVD schemes as options for scalar transport: Superbee and CHARM. Superbee is recommended for LES because it more accurately preserves the scalar variance for coarse grid solutions which are not expected to be smooth. Due to the gradient steepening applied in Superbee, however, the convergence degrades at small grid spacing for smooth solutions (the method will revert to a stair-step pattern instead of the exact solution). CHARM, though slightly more dissipative than Superbee, is convergent, and is therefore the better choice for DNS calculations where the flame front is well resolved. 


\section{Combustion and Extinction}

FDS versions 2 through 4 used a single parameter mixture fraction to track fuel and combustion product species. Among the issues of that approach was that it was unable to simulate extinction; heat release could be disabled but product formation could not. The release of FDS v5 brought with it a new species tracking approach using a lumped species approach to conserve computational resources. FDS v5 explicitly tracks unburned fuel and burned fuel (e.g. a lumped species consisting of all combustion products) and implicitly tracks the lumped species of air (e.g. everything that is not fuel or burned fuel) [6]. Since combustion products are transported as a distinct species, true extinction can be modeled in FDS v5 (no heat release and no product formation). For the purpose of this study, a two-parameter mixture fraction model was used with fixed yields for soot and carbon monoxide:

$Z=Z_{1}+Z_{2} ; \quad Z_{1}=Y_{F} ; \quad Z_{2}=\frac{W_{F}}{\left[x-v_{C O}-\left(1-X_{H}\right) v_{S}\right] W_{C O 2}} Y_{C O 2}$

The FDS default values of $v_{S}=0.01 \mathrm{~kg} / \mathrm{kg}$ and $v_{C O}=0.0 \mathrm{~kg} / \mathrm{kg}$ were used. Thermal radiation was modeled using the grey-gas approach, with the radiative fraction obtained from the local gas temperature and absorption coefficient in DNS mode, and using a fixed radiative fraction of 0.35 in LES mode.

Since the primary use of FDS is for large scale simulations in the built environment, the FDS combustion model reflects the realities of that usage. Namely that grid sizes of multiple centimeters are common and that fuels are often not simple chemical compounds for which reaction rate data exists. The FDS combustion model used throughout this work (for both DNS and LES calculations) assumes infinitely fast kinetics with the amount of combustion limited based on the local mixing rate. The local mixing rate is either the time step for a DNS calculation (DNS is presumed to fully resolve the flow field) or on a mixing time determined from using the turbulent viscosity (e.g. use the LES model to determine degree of mixing). Combustion of fuel is limited to that which can mix over a time step.

The extinction model in FDS uses the concept of a limiting flame temperature [7], below which combustion is not supported. In brief the model examines a grid cell and determines if combustion of the fuel in that cell as a stoichiometric mixture would raise the temperature of that mixture in excess of the limiting flame temperature. As initially developed in FDS v2, this model examined only the fuel and oxygen concentrations and assumed the gas was air with a constant specific heat. The resulting criterion is a linear function that gives the limiting oxygen concentration as a function of the local temperature. This approach had two fundamental problems. First, specific heat from ambient temperature to flame temperature is not constant (for air it increases $25 \%$ ). Second, diluent gasses can have specific heats that are significantly different than air, for example air at room temperature has a specific heat of $1.0 \mathrm{~kJ} / \mathrm{kg} \cdot \mathrm{K}$ and water vapor is $1.9 \mathrm{~kJ} / \mathrm{kg} \cdot \mathrm{K}$. Combined, these two issues resulted in poor predictions of extinction by FDS.

The two issues of temperature and species dependence were addressed by implementing a modified criterion, which is the subject of this paper. In the new approach, the sensible enthalpies of the fuel and the local gas mixture without the fuel are computed at both the gas cell temperature and the limiting flame temperature using temperature dependent look up tables for all the species present. The changes due to stoichiometric combustion in the mass fractions of fuel and the gas mixture without fuel are

$\Delta Y_{F}=\operatorname{MIN}\left(Y_{F}, Y_{O 2} / s\right), \quad \Delta Y_{g}=s \Delta Y_{F} \frac{1-Y_{F}}{Y_{O 2}} ; \quad s=\frac{v_{O 2} W_{O 2}}{W_{F}}$

The enthalpy differences are

$\Delta h_{F}=h_{F}\left(T_{L}\right)-h_{F}\left(T_{g}\right) ; \quad \Delta h_{g}=h_{g}\left(T_{L}\right)-h_{g}\left(T_{g}\right)$

with 
$h_{g}=\sum_{\alpha} Y_{\alpha} h_{\alpha} ; \quad h_{\alpha}(T)=\int_{T_{0}}^{T} c_{p, \alpha}\left(T^{\prime}\right) d T^{\prime}$

Combustion is not allowed and local extinction occurs if the enthalpy difference between the two temperatures is greater than the heat of combustion for that mixture (i.e. not enough energy is released to raise the gas temperature to the limiting flame temperature):

$\Delta Y_{F} \Delta h_{F}+\Delta Y_{g} \Delta h_{g}>\Delta Y_{F} \Delta H_{C}$

For DNS calculations, an additional constraint for combustion was used in this work, preventing combustion if the local gas temperature in the cell is below the auto-ignition temperature of the fuel.

Finally, it is pointed out that the flame extinguishment criterion does not address subgrid-scale variations, and it does not include the effects of strain.

\section{The Cup-burner Model}

The cup-burner [2] consists of a vertical round chimney $533 \pm 10 \mathrm{~mm}$ in height and $85 \pm 2 \mathrm{~mm}$ in inner diameter. An air-agent mixture is admitted to the chimney through a diffuser at the bottom of the chimney. A round fuel cup 28-31 mm in outer diameter and 1-2 mm wall thickness is on the axis of the chimney such that the rim of the cup is $235 \mathrm{~mm}$ above the chimney bottom. To save on CPU time, only a part of the apparatus was modeled. An axisymmetric two-dimensional grid was used with a spatial resolution of $0.5 \mathrm{~mm}$. There were 84 cells in the radial direction, and 480 cells in the axial direction. The FDS model was run in DNS mode. The oxidizer inflow boundary was located $85 \mathrm{~mm}$ below the fuel inflow boundary. The cup was $28 \mathrm{~mm}$ in inner diameter. The rim of the cup was $1 \mathrm{~mm}$ thick and $1 \mathrm{~mm}$ high. A surface temperature of $300{ }^{\circ} \mathrm{C}$ was applied to the rim. The chimney wall was a non-reacting solid surface with a fixed wall temperature of $20^{\circ} \mathrm{C}$.

The oxidizer inflow boundary was a simple inflow vent pushing a mixture of dry air and a gaseous suppressant into the chimney at $20^{\circ} \mathrm{C}$ (ambient) temperature. The mass fraction of the suppressant could be ramped up as a function of time to mimic the actual cup-burner experiment. Typically, the agent concentration was zero for a pre-burn time of a few seconds to allow for the flame to develop. Then, the agent concentration was increased to a level slightly below the extinguishing concentration, and ramped up over a time of about $30 \mathrm{~s}$ to a value that ensured flame extinguishment. For methane, the oxidizer inflow velocity was set to $0.107 \mathrm{~m} / \mathrm{s}$ to give a volumetric flow rate of $36 \mathrm{~L} / \mathrm{min}$ in the chimney. For n-heptane, the oxidizer inflow velocity was $0.118 \mathrm{~m} / \mathrm{s}$ for a flow rate of $39 \mathrm{~L} / \mathrm{min}$. These velocities and flow rates are typical for the cup-burner experiment, and correspond to the so-called 'plateau region' in a plot of the MEC vs. velocity for both gaseous and liquid fuels. In this region, the experimental MEC values are practically independent of the flow velocity [2].

For methane, the fuel inflow boundary was a simple inflow vent with a normal velocity of $0.92 \mathrm{~cm} / \mathrm{s}$ for an oxidizer to fuel velocity ratio of 11.6:1. For n-heptane, a liquid evaporation model was used, where the evaporation rate of the fuel is governed by the Clausius-Clapeyron equation. With $0.5 \mathrm{~mm}$ cell size, the cup diameter is spanned by 56 cells.

The suppressants considered in this study were common inert gases: $\mathrm{He}, \mathrm{Ar}, \mathrm{N}_{2}$, and $\mathrm{CO}_{2}$. It has been shown [8-10] that their flame suppression effect is essentially due to the heat capacity. In addition, this study also includes three halocarbon agents, namely trifluoromethane $\left(\mathrm{CHF}_{3}\right)$, pentafluoroethane $\left(\mathrm{C}_{2} \mathrm{HF}_{5}\right)$, and perfluorohexane $\left(\mathrm{C}_{6} \mathrm{~F}_{14}\right)$. Fluorinated agents are not purely thermal. When they dissociate in the flame, the free fluorine is irreversibly trapping radicals that are part of the oxidation chain. Despite this, the primary flame suppression effect of these agents has been attributed to their heat capacity $[11,12]$. On the other hand, it has been argued that $\mathrm{CHF}_{3}$ completely and exothermally dissociates in the flame, whereas the radical trapping offsets this effect, making $\mathrm{CHF}_{3}$ appear as a thermal agent [14]. The heat capacity data for these agents was taken from Ref. [13] in the form of 7-term NASA polynomials. The Lennard-Jones parameters for $\mathrm{CHF}_{3}$ and $\mathrm{C}_{2} \mathrm{HF}_{5}$ were taken from Ref. [14], and for $\mathrm{C}_{6} \mathrm{~F}_{14}$ from Ref. [15]. 
The suppressant concentrations in the simulations were measured by a point device positioned at the level of the rim and $2 \mathrm{~mm}$ outside the outer edge of the rim.

\section{RESULTS}

\section{Flame Structure}

Figure 1 shows the calculated structure of non-suppressed methane flame in the flame base region. The fuel inlet boundary is at $z=0$. The black square denotes the cup rim. Figure 1a shows contours of volumetric heat release rate (solid lines) and oxygen volume fraction (dashed lines). Figure 1b shows contours of temperature, and flow velocity vectors. The position of the peak heat release rate (the reaction kernel) is next to the inner edge of the rim $(r=14.0 \mathrm{~mm}, z=2.0 \mathrm{~mm})$. It is commonly said that the non-suppressed flame is attached to the cup rim. The gas temperature attains its maximum value higher above the burner, in the 'trailing diffusion flame'. The peak value is $1651^{\circ} \mathrm{C}$. The temperature in the reaction kernel is $1151^{\circ} \mathrm{C}$.

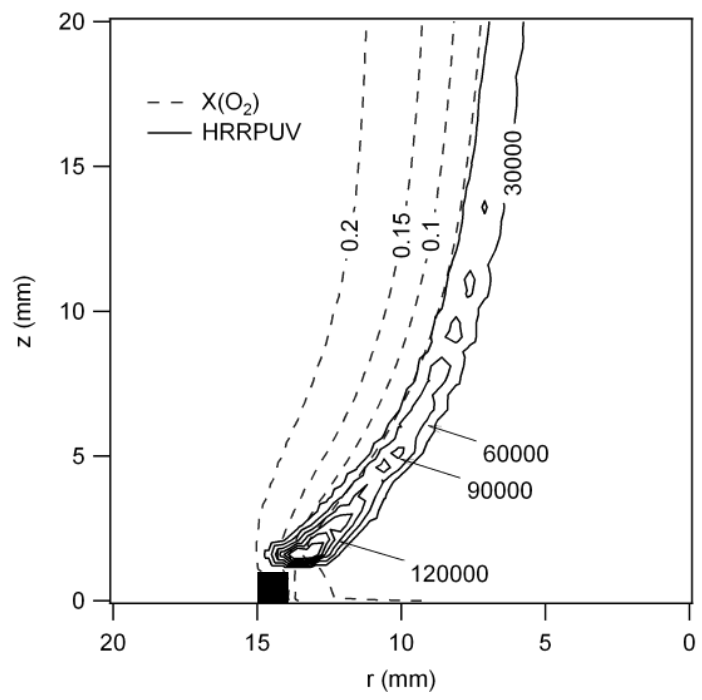

(a)

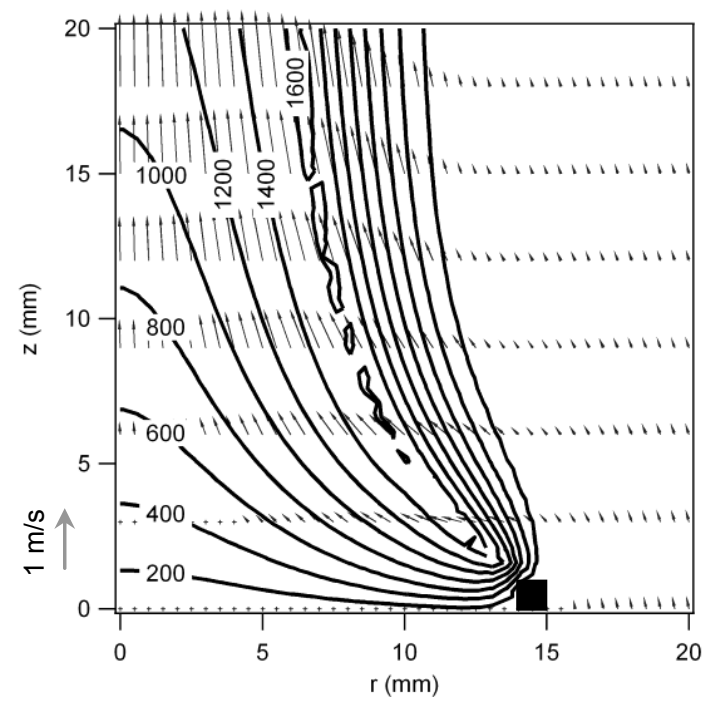

(b)

Fig. 1. Computed structure of non-suppressed methane flame: (a) contours of oxygen volume fraction and heat release rate per unit volume $\left(\mathrm{kW} / \mathrm{m}^{3}\right)$; (b) contours of temperature $\left({ }^{\circ} \mathrm{C}\right)$ and velocity vectors. The black squares denote the cup rim.

It is noted in Fig. 1 that the contours of volumetric heat release rate and temperature are not perfectly smooth, which may be an indication that the flow field is not fully resolved. In order to check this, the Kolmogorov length scale

$\eta=\left(\frac{(\mu / \rho)^{3}}{\varepsilon}\right)^{1 / 4}$

was estimated for the current problem using the calculated velocity and temperature data, and assuming the gas composition to be that of air. The dissipation rate $\varepsilon$ was estimated from

$\varepsilon=2(\mu / \rho) \mathbf{S}_{i j} \cdot \mathbf{S}_{i j}$

It was found that the smallest values for $\eta$ were about $0.5 \mathrm{~mm}$ for both methane and $\mathrm{n}$-heptane, and they were located on the oxidizer side of the flame where the largest velocity gradients are found. In the flame region, the values of $\eta$ were slightly above $1 \mathrm{~mm}$, and elsewhere between $1 \mathrm{~mm}$ and $3 \mathrm{~mm}$. 
For the n-heptane flame, the reaction kernel is $2 \mathrm{~mm}$ above the rim. The peak flame temperature is $1818{ }^{\circ} \mathrm{C}$ and is found at $r=11.0 \mathrm{~mm}$ and $z=9.5 \mathrm{~mm}$. It should be noted that due to the use of the liquid evaporation model, the n-heptane flame evolves to a steady-state over time. In all suppression simulations involving $\mathrm{n}$ heptane, a $10 \mathrm{~s}$ pre-burn time in co-flowing air was allowed before any agent was admitted to the chimney. The quasi steady-state burning rate of the n-heptane cup after $40 \mathrm{~s}$ was $0.0094 \mathrm{~g} / \mathrm{s}$, about a factor of 2 less than reported by Linteris [16].

To illustrate the effect of a thermal suppressant on the flame structure, Fig. 2 presents the calculated structure of a methane flame suppressed by carbon dioxide volume fraction of 0.168 which is slightly below the extinguishing concentration of 0.176. Compared to Fig. 1, the reaction kernel has slightly detached from the cup rim and moved upstream $(r=13.5 \mathrm{~mm}, z=2.5 \mathrm{~mm})$. The peak value of gas temperature is $979^{\circ} \mathrm{C}$, and the location of peak temperature $(r=12.5 \mathrm{~mm}, z=3.5 \mathrm{~mm})$ is close to the reaction kernel. The temperature in the reaction kernel is $863{ }^{\circ} \mathrm{C}$. Due to the lowered flame temperature, the flow velocities have decreased.

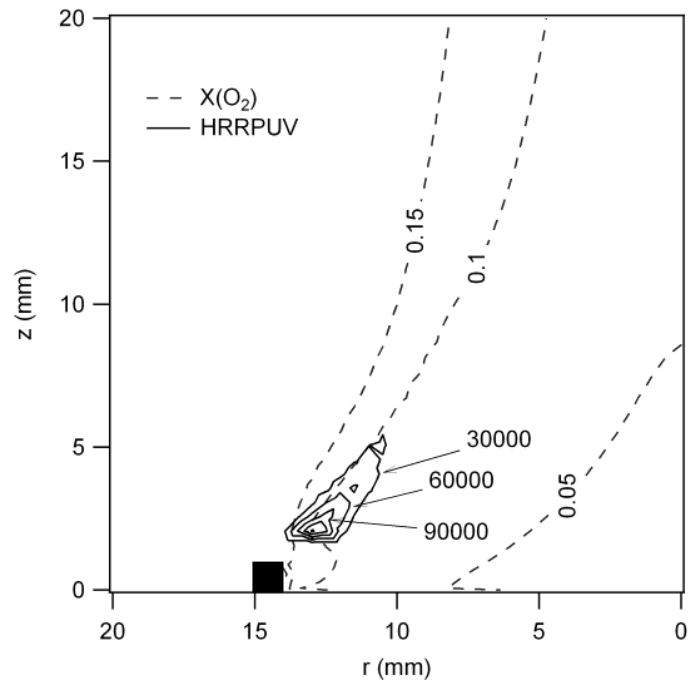

(a)

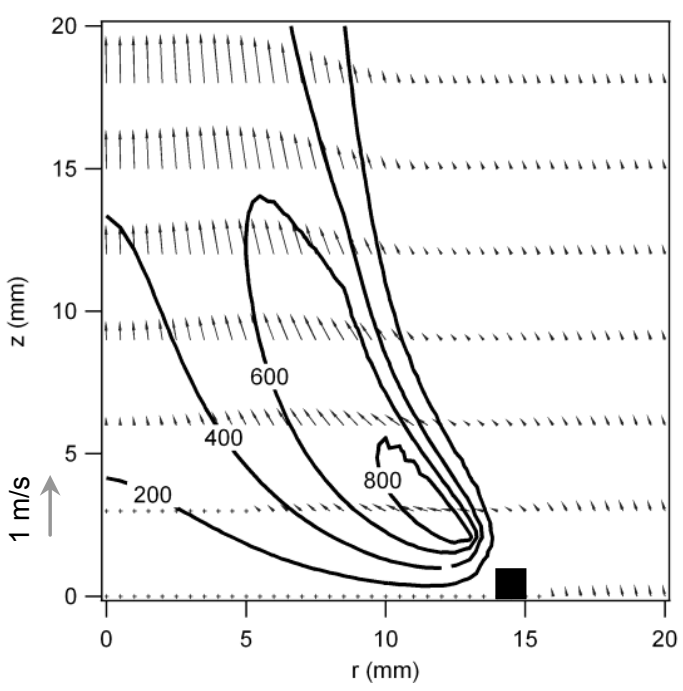

(b)

Fig. 2. Computed structure of methane flame suppressed with $\mathrm{X}\left(\mathrm{CO}_{2}\right)=0.168$ : (a) contours of oxygen volume fraction and heat release rate per unit volume $\left(\mathrm{kW} / \mathrm{m}^{3}\right)$; (b) contours of temperature $\left({ }^{\circ} \mathrm{C}\right)$ and velocity vectors. The black squares denote the cup rim.

\section{Minimum Extinguishing Concentrations}

The new flame suppression criterion requires two key input parameters from the user. These are the autoignition temperature (AIT), and the critical flame temperature (CFT). For simulations that resolve the flame sheet (and therefore the flame temperature), the AIT is an appropriate parameter to determine whether the fuel can undergo the initial chemical oxidation reactions leading to full oxidation. It is essentially a simple description of the activation energy for the rate-limiting step of the combustion reaction, but one that is readily applied to the lumped species formulation. The AIT values used for methane and n-heptane in this study were $540{ }^{\circ} \mathrm{C}$ and $215{ }^{\circ} \mathrm{C}$, respectively [7]. The use of AIT means that fuels do not ignite spontaneously, as is the case with the default mode of FDS (for which the default value of AIT is $0 \mathrm{~K}$ ). For ignition, a small hot object was placed above the center portion of the fuel inlet boundary, and removed once ignition had occurred, typically $0.5 \mathrm{~s}$ after the start of the simulation. Notice that for simulations not resolving the flame sheet, the use of AIT will not be appropriate.

There are no generally accepted CFT values for a given fuel-suppressant combination. For example, data shown in Ref. [7] suggests that the CFT depends on the fuel-air equivalence ratio. However, for purely thermal agents, it can be argued that since the effect of the suppressant is to cool the flame below a threshold temperature, the CFT for a given fuel should be independent of the (thermal) suppressant under fixed experimental conditions. Senecal [10] tested this assumption using STANJAN chemical equilibrium 
solver for n-heptane flames and using the experimentally observed MECs as the input. He found CFT values of $1571{ }^{\circ} \mathrm{C}$ and $1572{ }^{\circ} \mathrm{C}$ for $\mathrm{Ar}$ and $\mathrm{N}_{2}$, respectively, and a value of $1593{ }^{\circ} \mathrm{C}$ for $\mathrm{CO}_{2}$. The slightly higher value for $\mathrm{CO}_{2}$ was attributed to radiative heat loss due to $\mathrm{CO}_{2}$. Takahashi et al [17] took a similar approach for methane flames using UNICORN code in conjunction with GRI-V1.2 reaction mechanism, and found CFT values of $1602,1728,1630$, and $1654{ }^{\circ} \mathrm{C}$ for $\mathrm{Ar}, \mathrm{He}, \mathrm{N}_{2}$, and $\mathrm{CO}_{2}$, respectively. The CFT values used in this study were $1560{ }^{\circ} \mathrm{C}$ for $\mathrm{n}$-heptane, and $1630{ }^{\circ} \mathrm{C}$ for methane. These values were also applied for the halocarbon agents, although for example [17] suggests that the CFT for $\mathrm{CHF}_{3}$ in a methane flame is $1836^{\circ} \mathrm{C}$.

The experimental and calculated minimum extinguishing concentrations for the fuels and inert gasses and halocarbon agents involved in this study are given in Table 1 . The calculated results are presented for both previous and new extinguishing criteria of FDS v5. The data suggests that the new flame extinguishing criterion is able to capture the effect of the oxidizer heat capacity on the flame thermal balance. In particular, it is noted that the old approach was not able to predict flame extinguishment by He agent. The table also includes the FDS results for water vapor. They are conveniently obtained because there is currently no condensation in the model. To the best awareness of the authors, no experimental cup-burner data is available for water vapor due to practical difficulties caused by condensation. However, computational evidence exists to suggest that for all practical purposes, water vapor can be considered as an inert agent [18]. The flammability data by Coward and Jones [19] for methane-inert gas-air mixtures suggests that the inerting effectiveness of water vapor should fall between $\mathrm{N}_{2}$ and $\mathrm{CO}_{2}$.

Table 1. Minimum extinguishing concentrations (volume fraction) for methane and $n$-heptane fuels. The references are associated with experimental values.

\begin{tabular}{|c|c|c|c|c|c|}
\hline Fuel & Agent & FDS old & FDS new & Experiment & Reference \\
\hline $\mathrm{CH}_{4}$ & $\mathrm{He}$ & $>0.75$ & 0.279 & 0.27 & {$[17]$} \\
\cline { 2 - 6 } & $\mathrm{Ar}$ & 0.301 & 0.363 & 0.37 & {$[17]$} \\
\cline { 2 - 6 } & $\mathrm{N}_{2}$ & 0.301 & 0.294 & 0.26 & {$[17]$} \\
\cline { 2 - 6 } & $\mathrm{H}_{2} \mathrm{O}$ & 0.384 & 0.215 & $\mathrm{n} / \mathrm{a}$ & $\mathrm{n} / \mathrm{a}$ \\
\cline { 2 - 6 } & $\mathrm{CO}_{2}$ & 0.205 & 0.176 & 0.16 & {$[17]$} \\
\cline { 2 - 6 } & $\mathrm{CHF}_{3}$ & 0.138 & 0.114 & 0.11 & {$[14]$} \\
\hline \multirow{4}{*}{$\mathrm{n}_{7} \mathrm{H}_{16}$} & $\mathrm{He}$ & $>0.75$ & 0.348 & 0.32 & {$[7]$} \\
\cline { 2 - 6 } & $\mathrm{Ar}$ & 0.316 & 0.421 & $0.41^{\mathrm{a}}$ & {$[8-10,20,21]$} \\
\cline { 2 - 6 } & $\mathrm{N}_{2}$ & 0.329 & 0.339 & $0.32^{\mathrm{a}}$ & {$[8-10,20,21]$} \\
\cline { 2 - 6 } & $\mathrm{H}_{2} \mathrm{O}$ & 0.385 & 0.259 & $\mathrm{n} / \mathrm{a}$ & $\mathrm{n} / \mathrm{a}$ \\
\cline { 2 - 6 } & $\mathrm{CO}_{2}$ & 0.215 & 0.236 & $0.22^{\mathrm{a}}$ & {$[8-10,20,21]$} \\
\cline { 2 - 6 } & $\mathrm{CHF}_{3}$ & 0.149 & 0.165 & $0.13^{\mathrm{a}}$ & {$[21]$} \\
\cline { 2 - 6 } & $\mathrm{C}_{2} \mathrm{HF}_{5}$ & 0.088 & 0.106 & $0.09^{\mathrm{a}}$ & {$[20,21]$} \\
\cline { 2 - 6 } & $\mathrm{C}_{6} \mathrm{~F}_{14}$ & 0.032 & 0.042 & 0.04 & {$[21]$} \\
\hline
\end{tabular}

${ }^{\mathrm{a}}$ Average value over individual investigations.

One possibility to evaluate the model uncertainty is to follow the procedure outlined in the FDS validation guide [22]. This procedure enables computation of the model bias and uncertainty using pairs of predicted and experimental data points (such as presented in Table 1) along with the experimental error. The reader is referred to the validation guide for a detailed explanation.

The experimental accuracy of the cup-burner MEC values may be estimated by comparing the individual MEC value determinations for a fixed fuel-agent combination obtained from different laboratories. Such data is most abundant for $\mathrm{n}$-heptane and the most common inert gas agents of $\mathrm{Ar}, \mathrm{N}_{2}$ and $\mathrm{CO}_{2}$. Taking a conservative error estimate of $6 \%$ and applying that to all fuel-agent combinations, a bias factor of 1.09 and a relative uncertainty of $6.4 \%$ can be computed for the predictions with new extinguishing criterion. This indicates that the new model is in general over-predicting the MEC values and that the experimental and model uncertainties are close to each other. The reason for over-prediction can most likely be attributed to the choice of the CFT values, as shown by the sensitivity analysis below. 


\section{Sensitivity}

The sensitivity of the MEC values has been studied for spatial resolution, critical flame temperature, oxidizer stream velocity in the chimney, and auto-ignition temperature. Figure 3 presents the volumetric MEC results for spatial resolutions of $0.5 \mathrm{~mm}, 1 \mathrm{~mm}$, and $2 \mathrm{~mm}$ as a correlation between experimental and computed values. For $2 \mathrm{~mm}$ resolution, the rim height of the cup was $0 \mathrm{~mm}$, and the thickness of the rim was $2 \mathrm{~mm}$. Visual inspection of Fig. 3 suggests no obvious correlation between spatial resolution and MEC. An uncertainty analysis for the results with the new extinguishing criterion yields bias factors of $1.09,1.07$ and 1.03 and uncertainties of $6.4 \%, 6.5 \%$, and $11.2 \%$ for $0.5 \mathrm{~mm}, 1 \mathrm{~mm}$ and $2 \mathrm{~mm}$ resolutions, respectively. For comparison, an uncertainty analysis for the old extinguishing criterion yields bias factors of $1.28,1.26$ and 1.21 and uncertainties of $40 \%, 41 \%$, and $44 \%$ for $0.5 \mathrm{~mm}, 1 \mathrm{~mm}$ and $2 \mathrm{~mm}$ resolutions, respectively (assuming a MEC value of 0.75 for all He cases).

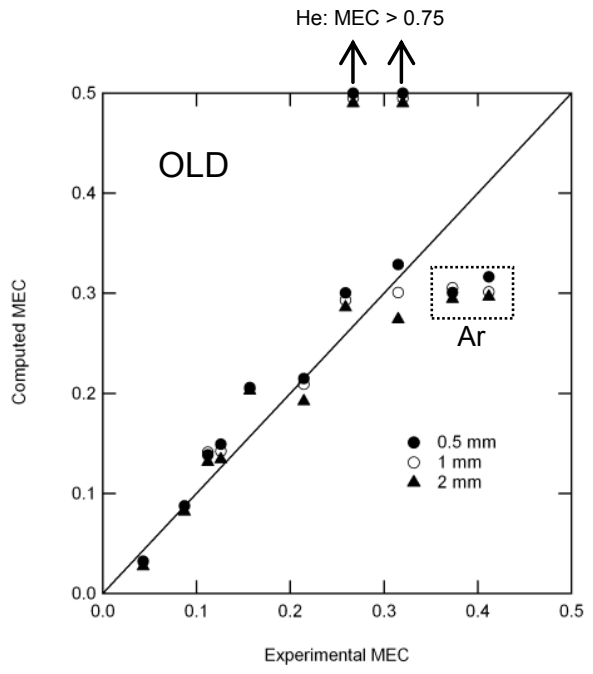

(a)

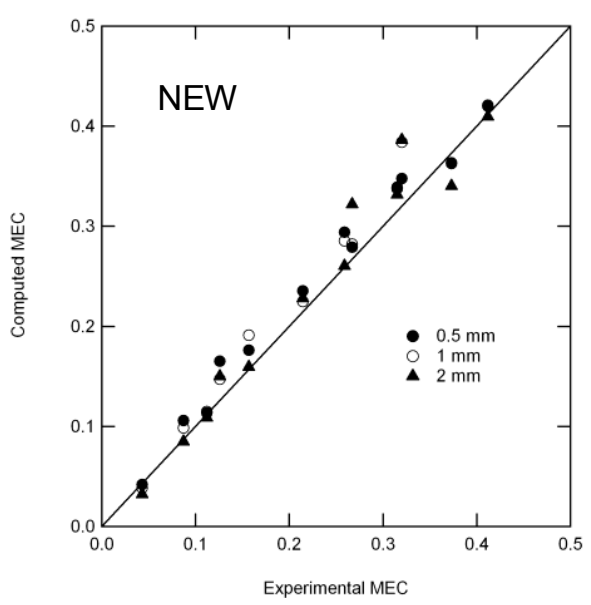

(b)

Fig. 3. Comparison of volumetric MEC values for spatial resolutions of $0.5,1$, and $2 \mathrm{~mm}$ to experimental data of Table 1: (a) old extinguishing criterion; (b) new extinguishing criterion.

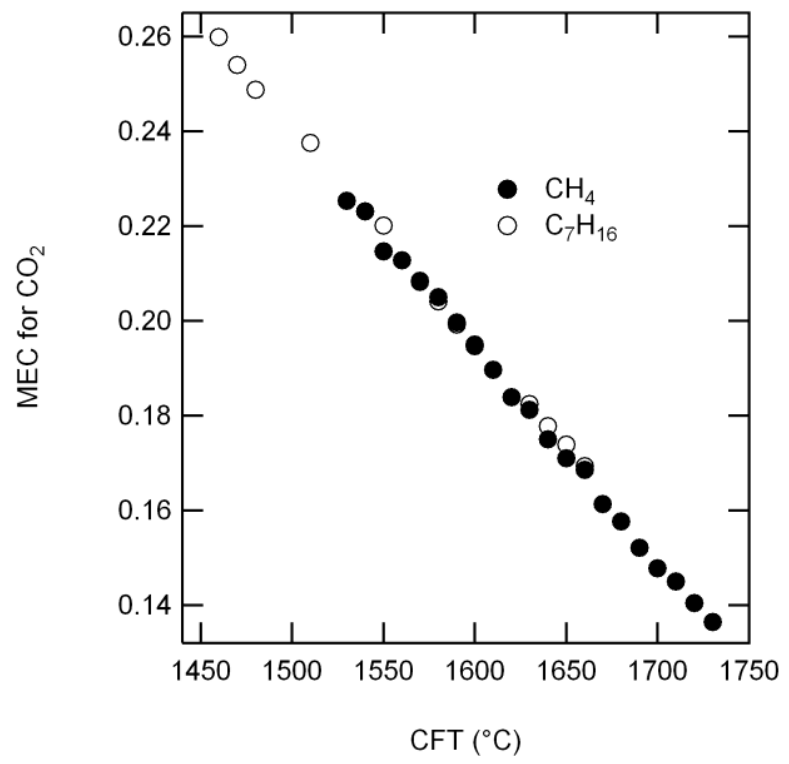

Fig. 4. Sensitivity of $\mathrm{CO}_{2} \mathrm{MEC}$ for critical flame temperature. 
The sensitivity of MEC for CFT was studied for $\mathrm{n}$-heptane and methane fuels and $\mathrm{CO}_{2}$ suppressant at grid resolution of $1 \mathrm{~mm}$ (see Fig. 4). Clearly, the MEC has a strong linear dependence on the CFT, which stresses the importance of a careful choice of the CFT. On the other hand, a bad choice for CFT should be observed as a large bias factor when performing the model uncertainty analysis.

The sensitivity of $\mathrm{He}$ and $\mathrm{CO}_{2}$ MEC for oxidizer flow velocity was studied for n-heptane fuel at grid resolution of $1 \mathrm{~mm}$ (Fig. 5). The MEC values remain essentially constant as a function of velocity, consistent with the concept of an experimentally observed plateau region. The scatter in the data reflects the accuracy of the MEC determination for $1 \mathrm{~mm}$ resolution. However, the data points for He at low oxidizer flow velocities deviate significantly from the plateau level. The right-hand side of Fig. 5 shows slices of the helium concentration and the heat release rate at a concentration slightly below extinguishment. It can be observed that the distribution of helium is not uniform in the chimney. In particular, helium is highly concentrated around the rim of the cup, which results in the lift-off of the flame. Above the rim, the flow field diverges and the helium concentration decreases to support a detached flame. Since the point device detecting the agent concentration is located right next to the rim, a higher than expected MEC is recorded. For flow velocities above $0.08 \mathrm{~m} / \mathrm{s}$, helium becomes more uniformly distributed. Since the molecular weight of $\mathrm{CO}_{2}$ is closer to air, $\mathrm{CO}_{2}$ concentration remains uniform even at low flow velocities.

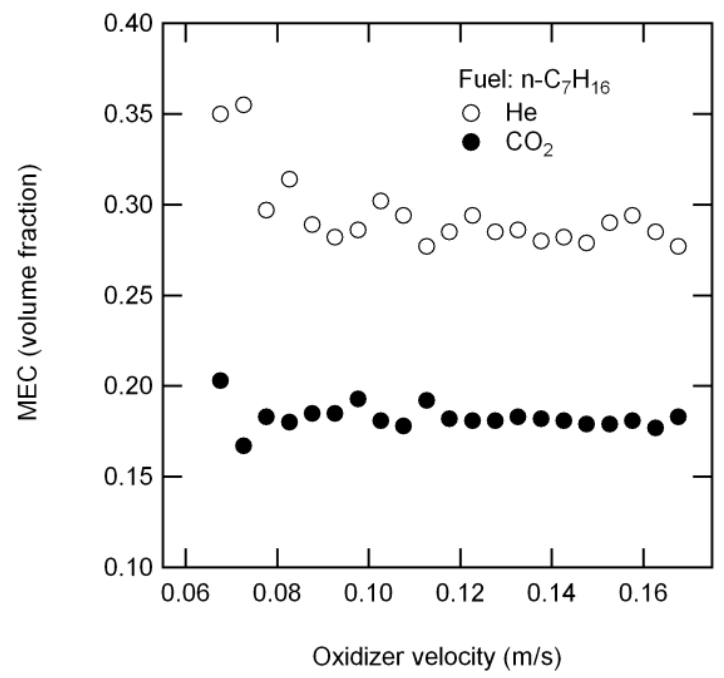

(a)

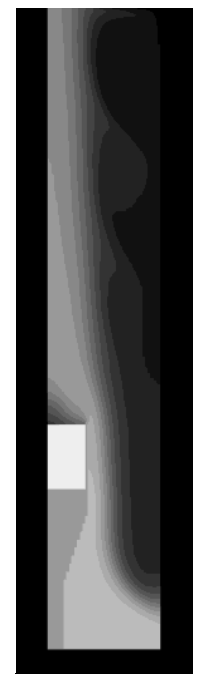

(b)

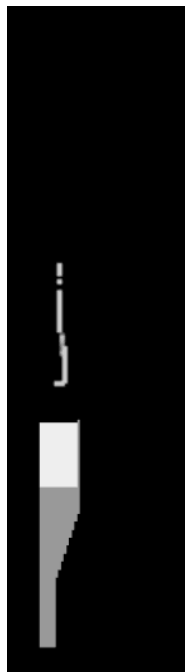

(c)

Fig. 5. (a) Sensitivity of $\mathrm{He}$ and $\mathrm{CO}_{2} \mathrm{MEC}$ for oxidizer flow velocity; (b) distribution of helium and; (c) heat release rate for flow velocity of $6.7 \mathrm{~cm} / \mathrm{s}$.

The sensitivity of MEC for auto-ignition temperature was studied for methane fuel at grid resolution of $1 \mathrm{~mm}$. Figure 6 shows the results for $\mathrm{He}$ and $\mathrm{CO}_{2}$. Of all suppressants involved in this study, $\mathrm{He}$ was the only one exhibiting a dependence on AIT. It can be noted that when the methane AIT is reduced to ambient temperature, FDS yields a MEC of about 0.37 for $\mathrm{He}$, a value that coincides with that for Ar. As monatomic ideal gases, $\mathrm{He}$ and $\mathrm{Ar}$ share the same specific heat on a molar basis. Based on computations involving full chemistry, Takahashi et al. [17] attributed the greater flame cooling effectiveness of He to its larger thermal conductivity. 


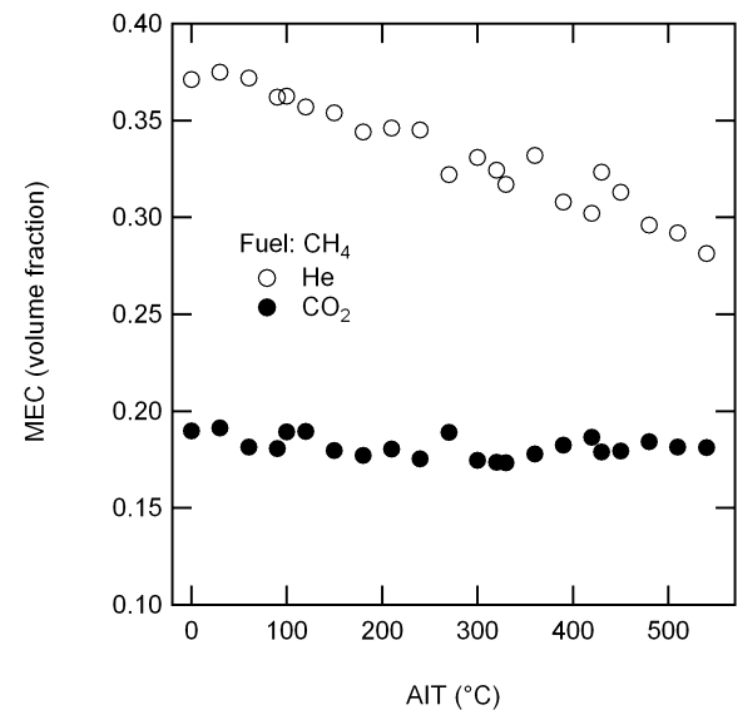

Fig. 6. Sensitivity of $\mathrm{He}$ and $\mathrm{CO}_{2} \mathrm{MEC}$ for auto-ignition temperature for methane fuel.

\section{FULL-SCALE APPLICATIONS}

Full-scale fire simulations often require spatial resolutions of $0.1 \mathrm{~m}$ or above. Such resolutions are too coarse to resolve the flame sheet and the flame temperature. An advantage of the new flame extinguishment formulation is that resolving the flame sheet is not required. The model evaluates the potential heat release in a volume and checks whether this energy can raise the temperature of the volume above a critical threshold value. To demonstrate this, a robust 3-D scaled-up co-flow set-up was implemented in the FDS input file. The arrangement consisted of a square-shaped vertical chimney measuring $4 \mathrm{~m} \times 4 \mathrm{~m}$ with a height of $12 \mathrm{~m}$. The oxidizer inflow boundary was at the bottom of the chimney. The oxidizer flow velocity was set to $0.83 \mathrm{~m} / \mathrm{s}$. The fuel inlet boundary measured $1.2 \mathrm{~m} \times 1.2 \mathrm{~m}$ and was located on top of a $3 \mathrm{~m}$ high obstacle placed at the bottom of the chimney. For methane fuel, a heat release rate per unit area of $1389 \mathrm{~kW} / \mathrm{m}^{2}$ was applied for a heat release rate of $2 \mathrm{MW}$. For $\mathrm{n}$-heptane, the liquid evaporation model yielded a heat release of about $4 \mathrm{MW}$. The grid resolution was $0.1 \mathrm{~m}$.

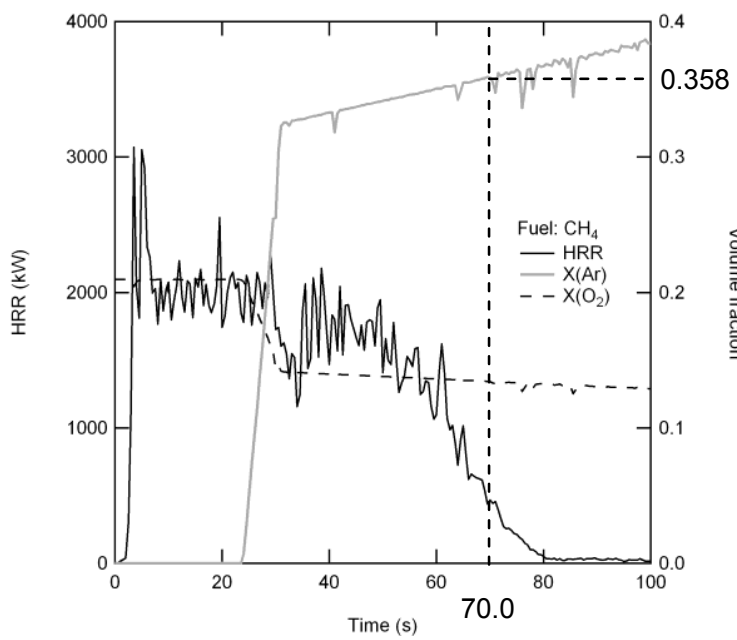

(a)

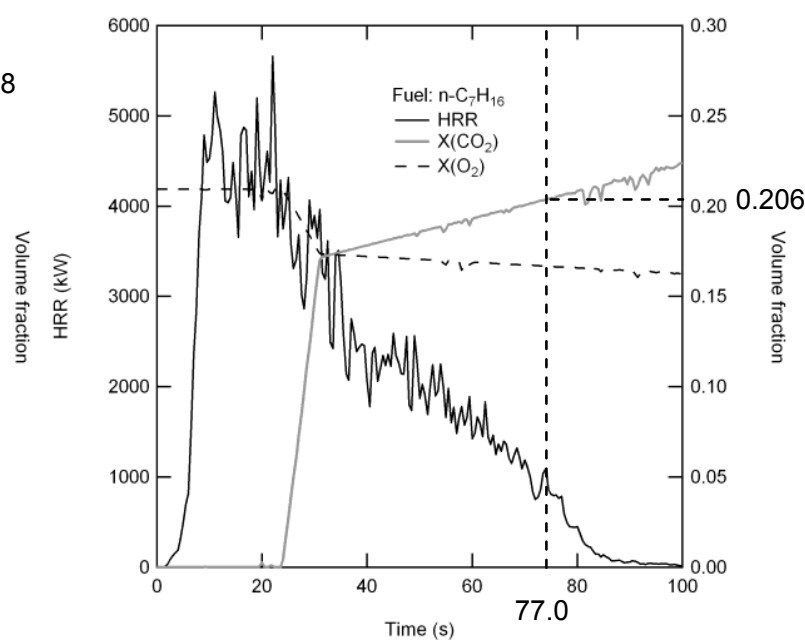

(b)

Fig. 7. Results of full-scale flame-extinguishing simulations: (a) $\mathrm{CH}_{4}-\mathrm{Ar}$; (b) $\mathrm{C}_{7} \mathrm{H}_{16}-\mathrm{CO}_{2}$. The moment of flame detachment (vertical dashed line) and corresponding agent concentration at flame base level are indicated. 


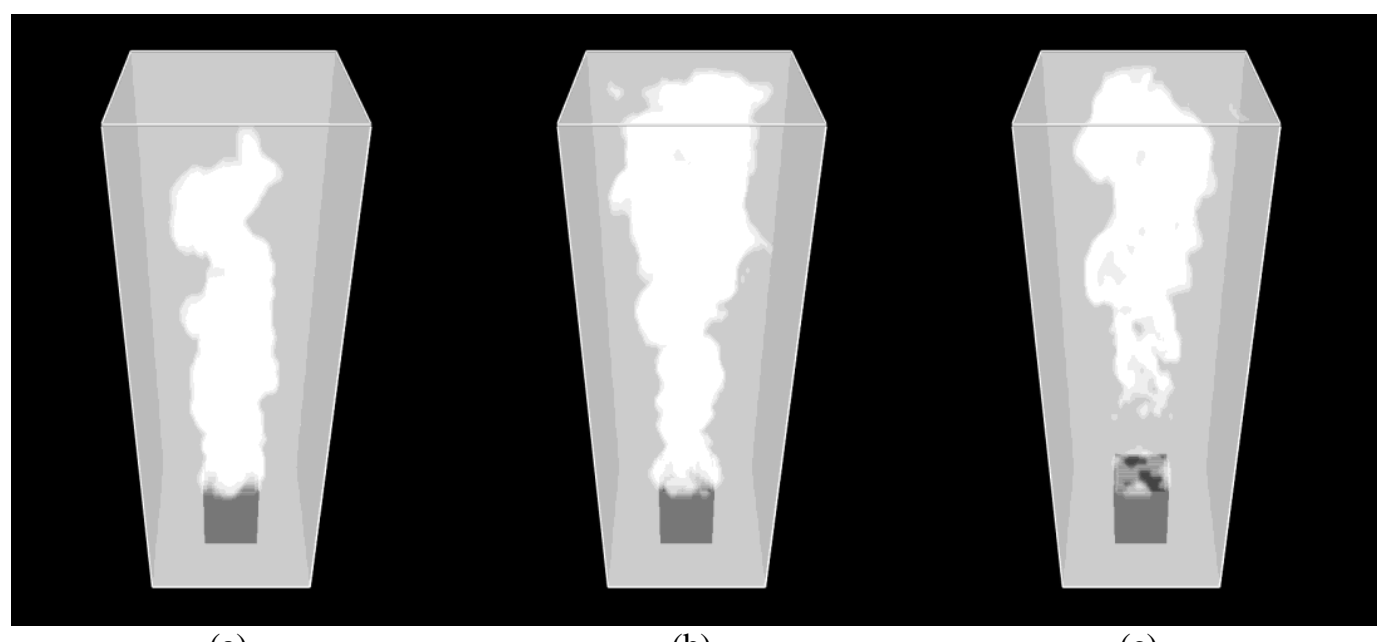

(a)

(b)

(c)

Fig. 8. Full-scale n-heptane flame suppressed by $\mathrm{CO}_{2}$ at: (a) $t=15.5 \mathrm{~s}$; (b) $t=53.0 \mathrm{~s}$; (c) $t=78.5 \mathrm{~s}$. See

Fig. 7b. The visible flame in the figures corresponds to a volumetric heat release lower cutoff value of $2 \mathrm{~kW} / \mathrm{m}^{3}$.

Figure 7 shows the heat release rate and volume fractions of inert gas agent and oxygen for two cases: $\mathrm{CH}_{4}-\mathrm{Ar}$ and $\mathrm{C}_{7} \mathrm{H}_{16}-\mathrm{CO}_{2}$. The point devices measuring the agent and oxygen concentrations were placed next to the rim, and were at times briefly engulfed in the turbulent flames. For both methane and n-heptane, the onset of the agent exposure leads to an initial decrease of the heat release rate. This is attributed to the lengthening of the flame (Fig. 8b) such that part of the unburnt fuel is convected out of the computational domain through the outflow boundary. Increasing the agent concentration eventually leads to the detachment of the flame base from the fuel inlet boundary (Fig. 8c). After this, the heat release rate drops to zero during a time of $10 \mathrm{~s}$ as the extinguishing concentration of agent moves upwards at $0.83 \mathrm{~m} / \mathrm{s}$. The extinguishing concentration, as measured by the point device next to the rim, corresponds to the detachment of the flame. The exact moment of detachment can only be determined with an accuracy of 1$2 \mathrm{~s}$.

From the full-scale simulations for $\mathrm{CH}_{4}$, MEC values of $0.358,0.285$, and 0.180 were determined for Ar, $\mathrm{N}_{2}$, and $\mathrm{CO}_{2}$, respectively, in fair agreement with the experimental cup-burner values of $0.37,0.26$, and 0.16. Similarly, for $\mathrm{C}_{7} \mathrm{H}_{16}$, full-scale MEC values of $0.397,0.320$, and 0.206 were determined, comparing well with the experimental cup-burner values of $0.41,0.32$, and 0.22 .

\section{CONCLUSIONS}

An improved flame extinguishing criterion was implemented in Fire Dynamics Simulator (FDS) for gaseous suppressants under the lumped species model with transport-limited combustion (infinitely fast chemistry). The model evaluates the enthalpy of the local gas mixture in a grid cell and determines if combustion of the fuel in that cell as a stoichiometric mixture would raise the temperature of that mixture in excess of the limiting flame temperature.

The model is designed specifically to predict flame extinguishment due to gaseous thermal suppression agents, in particular inert gasses. The model is not expected to work for highly strained flames, and it does not explicitly treat condensed phase agents. For example, if water droplets are approaching a flame but completely vaporize before the flame, the model should capture the suppression effect of water vapor. The effect of droplet vaporization in the flame is only accounted for through evaporative cooling of the flame.

With an improved capability to predict flame suppression in full scale, it is expected that FDS can be better applied to study the real-life performance of fire fighting systems. Of special importance is the improved capability to model the fire suppression effect of water vapor. This plays a significant role whenever there is potential for large fires in confined spaces that are protected by water based fire fighting systems. Examples of such cases are various types of machinery spaces, and increasingly also traffic tunnels. 


\section{ACKNOWLEDGEMENTS}

This research was carried out under the Fire Suppression RD project sponsored by the Safety and Security Programme of the Finnish Funding Agency for Technology and Innovation. Comments and suggestions by Dr. Gregory Linteris of NIST are gratefully acknowledged.

\section{REFERENCES}

[1] Grosshandler, W.L., "A research agenda for the next generation of performance-based design tools," Interflam -- Proceedings of the Eleventh International Conference, Interscience Communications, 2007, pp. 1219-1230.

[2] NFPA 2001, "Standard on Clean Agent Fire Extinguishing Systems," National Fire Protection Association, 2004, p. 90.

[3] McGrattan, K.B, Hostikka, S., Floyd, J.E., Baum, H., Rehm, R., Mell, W., and McDermott, R., "Fire Dynamics Simulator (Version 5) Technical Reference Guide. Volume 1: Mathematical Model," National Institute of Standards and Technology Report SP 1018-5, Gaithersburg, MD, 2010, 108 p.

[4] Roe, P.L., (1986) Characteristics-based schemes for the Euler equations, Ann. Rev. Fluid Mech. 18: 337-365, http://dx.doi.org/10.1146/annurev.fl.18.010186.002005

[5] Zhou, G., "Numerical simulations of physical discontinuities in single and multi-fluid flows for arbitrary Mach numbers," PhD Thesis, Chalmers University of Technology, Goteborg, Sweden, 1995.

[6] Floyd, J.E., McGrattan, K.B., (2009) Extending the mixture fraction concept to address underventilated fires, Fire Safety Journal 44: 291-300, http://dx.doi.org/10.1016/j.firesaf.2008.07.002

[7] Beyler, C.L., "Flammability Limits of Premixed and Diffusion Flames," The SFPE Handbook of Fire Protection Engineering ( $3^{\text {rd }} e d$ ), DiNenno P.J. (ed.), National Fire Protection Association, Quincy, MA 02269, 2002, p. 2/173.

[8] Saito, N., Ogawa, Y., Saso, Y., Liao, C., and Sakei, R., (1996) Flame-extinguishing concentrations and Peak Concentrations of $\mathrm{N}_{2}, \mathrm{Ar}, \mathrm{CO}_{2}$ and their mixtures for Hydrocarbon Fuels, Fire Safety Journal 27: 185-200, http://dx.doi.org/10.1016/S0379-7112(96)00060-4

[9] Sheinson, R.S., Penner-Hahn, J.E., and Indritz, D., (1989) The physical and chemical action of fire suppressants, Fire Safety Journal 15: 437-450, http://dx.doi.org/10.1016/0379-7112(89)90015-5

[10] Senecal, J.A., (2005) Flame extinguishing in the cup-burner by inert gases, Fire Safety Journal 40: 579-591, http://dx.doi.org/10.1016/j.firesaf.2005.05.008

[11] Liu, S., Soteriou, M.C., Colket, M.B., and Senecal, J.A., (2008) Determination of cup-burner extinguishing concentration using the perfectly stirred reactor model, Fire Safety Journal 43: 589597, http://dx.doi.org/10.1016/j.firesaf.2008.01.004

[12] Liu, S. and Colket, M.B., "Modeling Cup-burner Minimum Extinguishing Concentration of Halogenated Agents," SUPDET 2010 -- Proceedings of the Suppression, Detection and Signaling Research and Applications - A Technical Working Conference, National Fire Protection Association, Quincy, MA 02169, 2010.

[13] Burcat, A. and Ruscic, B., "Third Millennium Ideal Gas and Condensed Phase Thermochemical Database for Combustion with Updates from Active Thermochemical Tables," Argonne National Laboratory Report ANL-05/20, Argonne, IL, 2005.

[14] Katta, V.R., Takahashi, F., and Linteris, G.T., (2006) Fire-suppression characteristics of $\mathrm{CF}_{3} \mathrm{H}$ in a cup burner, Combustion and Flame 144: 645-661, http://dx.doi.org/10.1016/j.combustflame.2005.09.006 
[15] Chan, S.C., Bryant, J.T., Spicer, L.D., and Rabinovitch, B.S., (1970) Relative Cross Sections of Fluoroalkanes and Nitriles, Journal of Physical Chemistry 74: 2058-2064, http://10.1021/j100909a003

[16] Linteris, G.T., "Suppression of Cup-Burner Diffusion Flames by Super-Effective Chemical Inhibitors and Inert Compounds," HOTWC 2001 -- Proceedings of the Halon Options Technical Working Conference, New Mexico Engineering Research Institute, 2001, pp. 187-196.

[17] Takahashi, F., Linteris, G.T., and Katta, V.R., (2007) Extinguishment mechanisms of coflow diffusion flames in a cup-burner apparatus, Proceedings of the Combustion Institute, 31: 27212729, http://dx.doi.org/10.1016/j.proci.2006.08.112

[18] Dlugogorski, B.Z., Hichens, R.K., Kennedy, E.M., and Bozzelli, J.W., "Water vapour as an inerting agent," HOTWC 1997 -- Proceedings of the Halon Options Technical Working Conference, New Mexico Engineering Research Institute, 1997, pp. 7-18.

[19] Coward, H.F. and Jones, G.W., "Limits of Flammability of Gases and Vapors," US Bureau of Mines Bulletin No. 503, Washington, DC, 1952.

[20] Hamins, A., Gmurczyk, G.W., Grosshandler, W.L., Rehwoldt, R.G., Vazquez, I., Cleary, T.G., Presser, C., and Seshadri, K.G., "Evaluation of Alternative In-Flight Fire Suppressants for FullScale Testing in Simulated Aircraft Engine Nacelles and Dry Bays," National Institute of Standards and Technology Report SP 861, Grosshandler, W.L., Gann, R.G. and Pitts, W.M. (ed.), Gaithersburg, MD, 1994, pp 345-465.

[21] Moore, A.T., Weitz, C.A., and Tapscott, R.E., "An update on NMERI cup-burner test results," HOTWC 1996 -- Proceedings of the Halon Options Technical Working Conference, New Mexico Engineering Research Institute, 1996, pp. 551-564.

[22] McGrattan, K.B., Hostikka, S., Floyd, J.E., and McDermott, R., "Fire Dynamics Simulator (Version 5) Technical Reference Guide. Volume 3: Validation," National Institute of Standards and Technology Report SP 1018-5, Gaithersburg, MD, 2010, 298 p. 